\title{
Social representations of children in higher density housing; Enviable, inevitable or evil?
}

Dr Katrina Raynor, University of Melbourne, Melbourne School of Design

This text is the accepted version of:

Raynor, K. (2018). "Social representations of children in higher density housing: enviable, inevitable or evil?" Housing Studies: 1-20. https://doi.org/10.1080/02673037.2018.1424807

Acknowledgements: I am grateful to Professor Carolyn Whitzman and my anonymous reviewers for your thoughtful feedback on this paper. I also gratefully acknowledge Dr Matthew Palm for his assistance in creating the maps in this paper and helping me to provide a clearer narrative about the geographical distribution of children in Brisbane. Most of all, thank you to the interview participants that inspired this paper. 


\begin{abstract}
An increased focus on housing diversity in planning policy, international flows of capital and changing lifestyle preferences are resulting in increased higher density housing often marketed towards professional singles, couples without children and 'empty nesters.' Despite this, families with children currently dwell in higher density housing, either by choice or by necessity. This research identifies the social representations surrounding children in higher density housing in Australia's third largest city, Brisbane. It does this by analysing newspaper media published between 2007 and 2014 and through 46 interviews with residents and built-form professionals from Brisbane. The research finds four key representations; that children belong in the suburbs; increasing support for wealthy families in higher density housing, an economic argument for the lack of family-appropriate apartments and an increasing acceptance of medium density housing for younger households. This research draws attention to the winners and losers in housing debates and the 'common-sense' assumptions that impact housing outcomes.
\end{abstract}

\title{
Introduction
}

International trends towards compact city policies, increased residential development of inner-city sites and changing consumer lifestyles and preferences are causing rapid densification within many cities in the English-speaking developed world, including Australia (Newton \& Glackin, 2014), the US (Amati \& Taylor, 2010), the UK (Lambert \& Boddy, 2010), and New Zealand (Rowe, 2012). Within this context, apartments and townhouses are increasingly advocated by developers and planners as an attractive and cosmopolitan housing choice (Fullagar, Pavlidis, Reid, \& Lloyd, 2013). Sustainability imperatives have resulted in increasing support for high-density mixed-use urban forms (Howley, 2009), often based on their capacity to control outward urban expansion, revitalise inner-city areas, improve neighbourhood attractiveness and cohesion, encourage sustainable transport usage and preserve natural resources (Burchell, Listokin, \& Galley, 2000). Despite this, higher density housing remains a relative anomaly among many cities that have developed with predominantly detached, single-family dwellings and intensification policies are regarded with markedly different levels of enthusiasm (Raynor, Mayere, \& Matthews, 2017). In Brisbane, Australia's third largest city, low density, detached housing has traditionally been the norm but higher density is rapidly transforming the city, particularly in inner-city areas. Stand-alone, detached dwellings constituted $67 \%$ of all housing stock in 2016, decreasing substantially from 71\% in 2011 (Australian Bureau of Statistics, 2011). Over the same time period, attached dwellings (ranging from row houses to apartments) increased by $18 \%$ while the stock of detached houses increased by less than $1 \%$ (ABS 2016). These trends towards greater housing density will inevitably change the housing choices and lifestyles available to urban dwellers.

A key group likely to be impacted by these changes are families with children. The number of high rise apartments occupied by families with children in Brisbane almost doubled between 2011 and 2016, with almost $70 \%$ of these apartments located in the inner city (SGS Economics and Planning, 2017). Despite this, the needs of children and families are often ostracised from planning and development sectors, despite families constituting a growing group of consumers of higher density housing (Reid, Lloyd, \& O'Brien, 2017). Similarly, research now indicates the degree to which investor preferences and speculative profit-seeking developer behaviour rather than occupant demand has driven innercity densification (Raynor, Mayere, et al., 2017). In the UK (Lambert \& Boddy, 2010) and Australia (Birrell \& Healy, 2013), recent injections of investor capital in inner-city areas have been attributed with high levels of property vacancies, heightened risk of price volatility and the development of small, 
poorly-designed apartments with little long-term appeal to occupants, particularly families with children.

This paper seeks to identify how the newspaper media, residents of both high and low density neighbourhoods and built form professionals in Australia's third largest city, Brisbane, communicate about and socially represent higher density housing. The purpose of this paper is two-fold; firstly, it will identify key social representations of children in higher density occurring in the newspaper media and in the discourse of planners, developers, architects, peak organisations, local councillors and residents. Secondly, it will seek to draw attention to the power imbalances and planning implications evident in these social representations. In doing so, it will identify the culturally mediated processes through which attitudes to housing and child-rearing are expressed and discuss how housing consumption choices and expectations impact on different groups of people. The paper applies Social Representations Theory (SRT) to identify the embedded actions, ideas and values associated with higher density housing and children.

There are six sections in the paper. The first section situates this research within an existing body of housing research concerned with the way higher density housing is perceived and communicated about and the implications of these perceptions. The paper then outlines the utility of Social Representations Theory as an appropriate theoretical lens to complement and extend this area of research. The third section then briefly describes the methodology applied in this paper, including a description of the Q-methodology interviews and newspaper analysis undertaken in this research. The fourth section provides an overview of the housing and planning context in Brisbane with a focus on the expectations about intended occupiers of higher density housing implicit in policy. The paper then presents the key social representations evident in the newspaper media and in interviews with residents and built form professionals in Brisbane. The paper concludes with a discussion of the implications of these narratives and the ways these narratives have served to subjugate or support the needs of children in higher density environments.

\section{Narratives of Children in Higher Density Housing}

This paper joins an existing body of scholarship that investigates entrenched perceptions of housing types and associated notions of 'typical' residents. Currently, higher density housing provides an important, affordable housing option for families with children in cities in Australia (Easthope \& Tice, 2011; Randolph \& Tice, 2013) and internationally (Revington \& Townsend, 2016). Families live in these homes either by choice or by necessity. Research suggests that a sub-set of families with children choose to live in inner-city areas due to preferences for inner-city life-styles and employment opportunities (Carroll, Witten, \& Kearns, 2011; Lilius, 2014). Similarly, the limited research undertaken with children living in high density inner city settings suggests that many of them enjoy the proximity to street life and shopping as much as their parents (Whitzman \& Mizrachi, 2012). Kelly (2011) suggests that many families would be willing to move into higher density housing but are constrained by a lack of appropriate and affordable housing choices or a lack of child-friendly infrastructure in inner-city areas. Easthope and Tice's (2011) statistical analysis in Sydney's Olympic Park suggests that, particularly in middle ring suburbs characterised by high levels of lower income families, new higher density housing may rapidly become occupied by significant proportions of families with children.

Despite the propensity for children to occupy higher density housing, Australian cities are often critiqued for lacking child-friendly infrastructure (Gleeson \& Sipe, 2006). This lack of child-friendly infrastructure and housing choices in higher density areas can be partially attributed to entrenched social representations about life stages and appropriate housing choices. These representations are important as "normative views on what should be going on at certain stages of people's lives and the 
places in which these life stages should be lived often guide policies and public statements about cities" (Fincher \& Jacobs, 1998, p. 50). Cities are typically produced for specific social relations (Goodsell, 2013) and this is reflected in cities designed without children in mind.

According to Davison (2017), anglo-celtic society has associated the suburb with the aesthetic, moral, sanitary and social aspirations of the urban middle class since the $1840 \mathrm{~s}$. While single family detached dwellings continue to be associated with inward-looking, bounded and family-oriented home places, there is a pervasive discursive construction of high-rise developments as homes for childless households more interested in lifestyle than family (Fincher \& Gooder, 2007). Fincher (2004) found that, despite claiming to support socially innovative conceptions of housing consumers, developer and planner expectations of apartment dwellers in Melbourne continued to conform to existing apartment stereotypes. Similarly, Fullagar et al. (2013) and Costello (2005) comment on the gendered, generational and life-style focused delineations applied to 'acceptable' housing choices.

According to Costello (2005) and Langlois (2012), planning and development discourses as to the appropriateness of high rise development for families, wealthy households and 'empty nesters' has changed markedly in the decades since the 1960s. While high-rise was originally associated with social housing and deviance, it has changed to represent lifestyle-focused luxury housing. The media, historical events and social context have played a key role in mediating these discourses about housing. For instance, marketing images in Brisbane, Australia, recreate "an idealised neoliberal space of privileged freedom - safe, sophisticated urbanism" (Fullagar et al., 2013, p. 291). These images are associated with the targeted consumers; anglo-celtic, young or 'empty nester' heterosexual couples. The privileging of these groups comes with an associated silencing of 'inappropriate' consumers, such as the elderly, non-white cultural groups and children.

These narratives are important as they can shape development outcomes and planning policy. According to Randolph (2006, p. 5), normative views about family and density have resulted in "childblind" strategic planning and "higher density centres... built essentially for the childless in mind." Research in Melbourne and Sydney identifies widely disparate markets for higher density housing, including a high proportion of lower income households with children, despite planning policies that rarely reflect this fact (Randolph \& Tice, 2013). Taking the needs of families and children seriously necessitates reconsidering the management of higher density developments to avoid overly regulating family life. It also involves adjusting the design of apartments and urban areas to allow for quality play areas, safety measures, creation of amenities for young people and flexible housing to accommodate changing family structures and needs (Easthope \& Tice, 2011). This goal is both attainable and necessary but has often been silenced by pervasive views that families and children will not occupy higher density housing (Carroll et al., 2011). For this reason, understanding representations of housing types and appropriate residents is important. The literature recounted above focused on planning and developer narratives (Fincher, 2004, 2007), media discourses (Costello, 2005), branding strategies (Langlois, 2012) and marketing images (Fullagar et al., 2013) to identify representations of higher density housing. Another useful and complementary approach is the use of Social Representations Theory.

\section{Introducing Social Representations Theory}

Social Representations Theory, derived from social psychology, is a useful theoretical framework with which to identify how 'common sense' understandings of children in higher density housing are collectively constructed and circulated. Social representations (SR) are both "a code for social exchange and a code for naming and classifying unambiguously the various aspects of their world" (Moscovici, 1973, p. xvii) and have been conceptualised both as a process and a product. As a social 
process of communication and discourse, social representations generate and elaborate meanings and social objects. It is a process individuals and groups engage in to understand the world in which they live and to create a particular social reality. As a product, they constitute structures of knowledge and symbols that are shared with other people in a group or society and influence how these people discuss, conceptualise and react to phenomena (Wagner et al., 1999).

As SR enable dialogue and argumentation, they inform everyday politics and the normative politics of everyday, legal, institutional and policy debates (Howarth, Andreouli, \& Kessi, 2013). They determine what forms of action are thinkable and unthinkable and therefore draw the boundaries of the possible in specific contexts (Elcheroth, Doise, \& Reicher, 2011). In this way, they help to define what constitutes a 'problem' and influence the discussion of potential 'solutions' through the categorisation, labelling and prioritising of the issues in the debate. They are not merely descriptive, telling people how things are; they also function to tell people how things should be, and how individuals should behave in order to be consistent with general norms, values and social expectations (Radu \& Redien-Collot, 2008). For this reason, they are intrinsically linked to action and can be viewed as an influencing factor in processes of urban development, housing consumption and urban planning.

SRT assumes that individuals and groups deal with novel phenomena through a process of 'symbolic coping' that involves adopting collective images or representations that are linked to phenomena that are more familiar. This occurs through two processes: anchoring and objectification. These processes are the contents of communication that work to make the unfamiliar familiar and integrate novelty into a more understandable format (Wagner et al., 1999). Anchoring involves the naming and classifying of novel encounters, ideas and things in order to furnish social groups with a basic understanding of a novel concept (Wagner \& Hayes, 2005). An example of this is neighbourhood change and community opposition being anchored in more easily understandable and commonly shared notions of war, battle or population displacement. The process of objectification results in the construction of an icon, metaphor or trope which comes to stand for the new phenomenon or idea (Höijer, 2010). This makes the concept more concrete and easier to understand and drives mutations in 'common sense' over time (Joffe, 2003, p. 63). For example, Raynor, Matthews, and Mayere (2015) found that newspaper media objectified projected built form growth in Brisbane using imagery such as "Manhattanisation," "an LA skyline" or "Dubai-scale growth." In this way, the complex notion of population growth and built form changes were translated into icons drawn from a shared repository of images available to the newspaper audience. This paper investigates the anchoring and objectification apparent in social representations of families and children in higher density housing.

\section{Q-methodology interviews and media analysis; A mixed-methods approach to identifying social representations}

This research is part of a larger body of work conducted in 2015 pertaining to social representations of urban consolidation communicated in the Brisbane newspaper media (Raynor et al., 2015; Raynor, Matthews, \& Mayere, 2017) and in Q-methodology interviews with key Brisbane stakeholders (Raynor, Mayere, et al., 2017). The research did not apply a researcher-imposed definition of higher density housing, instead identifying how the newspaper media and interview participants defined the concept. The decision to combine interviews and media analysis is common within social representation scholarship as it offers a way to discover both how individuals conceptualise the topic in informal discussion and also the ideas circulating in society and communicated in the media (Bauer \& Gaskell, 1999).

The research draws upon a content analysis of 440 newspaper articles published between 2007 and 2014 in state-wide (The Courier Mail and The Sunday Mail), metropolitan (The Brisbane Times) and local (The Northside Chronicle and The South-East Advertiser) newspapers. Articles were collected 
from the online repository 'Factiva' using the search terms ["high* density" OR "urban consolidation" OR infill]. "High* density" and "infill" were added as search terms as "urban consolidation" is an academic term with little application in media articles and common parlance, and therefore returned few results. These articles were read and thematically coded using NVIVO.

The research also uses content from 46 recorded and transcribed Q-methodology interviews conducted in 2015 with 2 architects, 8 planners, 7 developers, 4 peak organisations and 2 local councillors and 23 residents from high, medium and low density neighbourhoods from Brisbane. These interview subjects were strategically selected to represent the greatest theoretical diversity of perspectives. The researcher recruited built form professionals affiliated with high and low density development and residents with varying degrees of involvement with community opposition or development processes. Snowball sampling was also used to identify interview subjects. See Figure 1 for a breakdown of participants.

\section{INSERT FIGURE 1 HERE}

Q-methodology involves a card-sorting activity and interview process that requires participants to rank statements from 'most agree' to 'least agree' and explain why they have chosen to rank them in that way (See Raynor, Mayere, et al., 2017 for a more detailed description of this process). The interviews in this study lasted about 60 minutes and were recorded and transcribed, creating a valuable source of data on the social representations expressed by Q-study participants. It was these responses that were analysed within this study. While these interviews prompted participants to respond to 50 statements about a variety of topics in relation to urban consolidation and higher density housing, it included several direct references to children and family and ideal apartment dwellers. Statements included "Apartments are only suitable for investors and the young, trendy innercity cafe crowd," "As much as Gen $Y$ is all about convenience, I think once they start to pair up and have kids they'll still want to move to the suburbs with some grass under their feet," and "Bringing up kids in higher density is actually easier because you have better access to high quality parks and other facilities." Similarly, several statements elicited opinions about children and family without explicitly mentioning these topics. Statements included; "I don't really need to buy a house. If I never saw anything I liked, or could afford, I'd be happy to rent."

The content of both the interviews and the newspaper articles were thematically coded using NVIVO to identify social representations, as evidenced by instances of anchoring and objectification. These themes emerged organically using grounded theory. The application of grounded theory is theoretically consistent with this study as it is concerned with the "discovery of theory from data systematically obtained from social research" (Glaser \& Strauss, 1967, p. 2) rather than the testing of a priori theories. In line with grounded theory, inductive analysis of interview transcripts and newspaper articles resulted in the identification of categories and codes and involved the iterative comparison of data and concepts to build a more refined picture of the topic. The researcher identified instances of anchoring and objectification through this process through attention to the use of metaphors, imagery, common-sense theories and classifications.

\section{Introducing Brisbane}


This research focuses on Brisbane, Australia's third largest city. Brisbane is located in the South East Queensland (SEQ) region, one of the fastest growing regions in Australia (Steele \& Dodson, 2014). Much of Brisbane's future growth is projected to occur in higher density areas as the Southeast Queensland Regional Plan 2009 includes a goal for at least $88 \%$ of all dwellings predicted to be developed between 2006 and 2031 in Brisbane to be delivered on infill sites at higher densities. In addition, The Brisbane City Plan 2014 advocates a series of Growth Nodes designed to concentrate housing on selected transport corridors co-located with commercial, recreation and retail land uses. This constitutes a substantial departure from Brisbane's traditionally low-density, dispersed built form.

It is important to note that this research investigated social representations of higher density housing without specifically referring to inner-city areas. The media and interview respondents tended to conflate 'higher density housing' and the 'inner-city.' As figures $2 \mathrm{a}$ and $2 \mathrm{~d}$ demonstrate, the suburbs with the highest population densities and highest numbers of apartments are predominantly located within $5 \mathrm{~km}$ of the $\mathrm{CBD}$, with some notable exceptions. These inner-city suburbs are characterised by a lower proportion of households with children, particularly in the CBD and the adjacent suburbs of Spring Hill, Fortitude Valley, New Farm and Kangaroo Point (see figure 2b). Despite this, in other higher density suburbs such as West End, Highgate Hill and Milton, up to $15 \%$ of households contain children and up to $20 \%$ of occupied apartments contain children (SGS Economics and Planning, 2017). This illustrates that, while inner-city Brisbane is characterised by lower proportions of households with children, there are significant concentrations of children living in higher density housing in specific suburbs. 

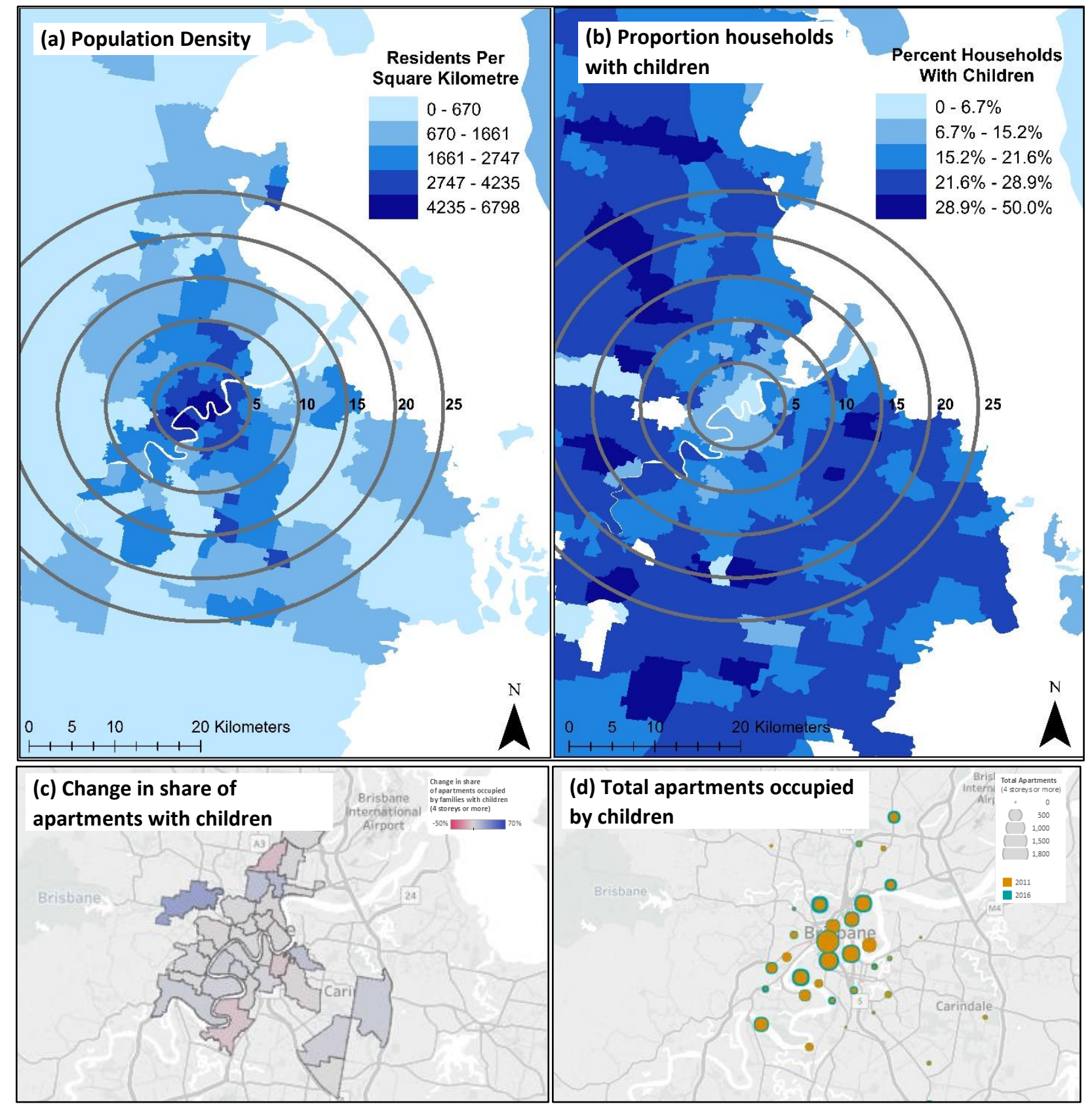

Figure 2. Maps showing spatial distribution of population density, households with children and apartments with children

Source for (a) and (b). ABS, 2017, Created by Palm, M

Source for (c) and (d). SGS Economics and Planning, 2017

While the demographics of Brisbane are changing, this is yet to be substantially reflected in housing and planning policy. Newspaper articles entitled "Families in city apartments: The social change our planners missed" accuse planners and politicians of ignoring or mistaking future trends (Moore, 2017). At the same time, inner-city schools exceed capacity and there has been substantial controversy and media attention surrounding the sale of Government-owned inner-city sites that could have been used for educational facilities. The Brisbane City Plan contains very few references to children and the City Centre Master Plan contains no specific child-friendly planning policies for the inner city beyond a goal to "build opportunities for both children and adults to play in the city centre" (Brisbane City 
Council, 2014, p. 163). In addition, apartment development in the five years leading to 2016 was almost entirely geared to investor appetite rather than owner-occupiers, resulting in a substantial concentration of one and two-bedroom units (Place Advisory, 2016).

\section{Enviable, Inevitable and Evil social representations of children in Higher Density Housing}

The media analysis and interviews revealed four key social representations pertaining to children and families and their relationship with various housing forms. The identified social representations, related to urban areas, apartments, suburbia, market mechanisms and housing affordability, have the capacity to shape how housing is delivered and consumed. These social representations, named 'Kids Belong in Suburbia,' 'Families can live in apartments (with caveats), 'It's Just Economics' and 'Do it for the Kids' constitute key attitudes, ideas and common-sense understandings circulating in society. Whilst literature has investigated the various meanings of home (Somerville, 1992), emotional responses to housing markets (Christie, Smith, \& Munro, 2008) and perceptions of various housing forms (Fincher, 2004), this study takes a broader view of children in higher density housing that encompasses overlapping and co-occurring ideas about home, family, lifestyle, economics, neighbourhood change and social and intergenerational justice. The wide-ranging nature of these topics is reflective of the tendency of research conducted within social representations theory to allow categories to emerge from the data without imposing a priori boundaries. Social representations are "images that condense manifold meanings that allow people to interpret what is happening; categories which serve to classify circumstances, phenomena and individuals with whom we deal; theories which permit us to establish facts about them" (Jodelet, 1991, p. 14). The following sections will describe these social representations in greater detail, highlighting the images, categories and theories embedded in shared common-sense representations of higher density housing and children. While they do not reflect the full spectrum of ideas pertaining to this topic in Brisbane nor a consensus, they begin to present a picture of systems of knowledge, mutual understandings and practices that individuals and groups use to make sense of their world (Howarth, 2001).Kids Belong in Suburbia

The pervasive social representation that children belong in detached, suburban housing is apparent in interviews and media reportage. Its power is evidenced both in explicit statements and through the implicit silencing of children from narratives of higher density housing. The notion that an apartment cannot be a 'proper' home to a 'family' has often been identified in literature (Fincher, 2004; Fincher \& Gooder, 2007) and was also reflected in the current study. As one resident currently dwelling in a townhouse noted;

"If I wanted to have a family I would want room because your lifestyle is going to change. When you are single or even when you have a partner but no kids then you don't really need your house. Your house is just to take a shower, have some dinner but everyone from my friends, everyone's dream is that once you have a family to move into a proper house. Because house and family - the idea is the same thing, no?" - Resident 1

This quotation is rich with associations and expectations about the value and meaning of home and the impact children have on it. Categorising detached housing as a 'proper home' is perhaps the most telling example of a hegemonic social representation as it demonstrates the unquestioned position of this housing form as the most appropriate for households with children. The idea that the birth of children signifies a significant shift in life stage and a commensurate change in housing needs is also deeply embedded in narratives. It was reflected in developer discourses stating;

"When people enter family formation they still tend to look for family housing, and apartments are not seen as family housing for a variety of reasons" - Developer 1 
As the above quotation reflects, detached housing continues to be anchored in notions of family and appropriate life stages. The use of the term 'family housing,' which often occurs in media and conversation is an example of anchoring as it explicitly classifies detached housing as a product for families. This is a powerful tool as it naturalises the notion that families live in detached houses and, by extension, negates the idea that a family could occupy an apartment. As Bourdieu (1985, p. 731) argued, "the most absolute recognition of legitimacy is nothing other than the apprehension of the everyday world as self-evident." Not only are suburbs seen as a more appropriate place to raise children, apartments and higher density areas are actively opposed as dangerous or deviant places. As two participants explained;

"I think suburbs are a better place to bring kids up just because they can walk around and do what they want and there isn't that safety issue." - Planner 1

And even more explicitly,

"I'd probably prefer not to raise kids in high density. I'd prefer to have less people these days with all the sickos and shit out there" - Developer 2

The sense of fear associated with higher-density housing serves to perpetuate a segregation between 'family-friendly' suburbs and the job-rich and amenity-rich inner areas of cities. This social representation is a challenge as the silencing of children in conceptions of the city has led to a lack of consideration of affordable housing for families, affordable child care options and transport systems designed to promote children's independent mobility (Warner \& Rukus, 2013).

Higher density housing is instead often portrayed as the realm of young urban professionals and wealthy empty nesters, divorced from traditional suburban, working class values. This idea is perhaps best reflected in the below quote from The Brisbane Times;

"The densification 'cool set', are all drinking their macchiatos and pontificating about what everyone else should do, Mr Salt said. "Real Australians, out in the 'burbs on a below average income could not afford apartments, townhouses, or duplexes. It's more a middle class solution." (Calligeros, 2010)

In this way, 'typical' high density dwellers are objectified as elites with professional jobs and little connection to suburban ideals. They are the 'cool set' because they embody a lifestyle considered both trendy and out of reach for "real Australians" (ibid). This is also reflected in the narratives of developers.

"The demographic around here is the 25 to 35 year olds who are not really interested in owning a home and want to spend their money going out and doing other things. That changes when you introduce kids" - Developer 3

Social representations also reveal themselves in what is silenced in conversation and in the media. By categorizing ideas and delimiting the pertinent aspects of a phenomenon certain concepts are necessarily excluded. This was illustrated in interviews when respondents were asked to respond to the comment; 'apartments are only suitable for investors and the young, trendy, inner-city café crowd.' Respondents overwhelmingly refuted this notion citing a broad range of household types that are catered for in higher density housing. These included empty nesters, business people, DINKS (double 
income no kids) and share houses - all household types without children. One high-density dweller, in commending the wide range of demographics in her apartment building said the following;

"I would say the biggest percentage of folk in the most expensive ones are retirees or people approaching retirement... We have quite a few young professionals, some non-professional blue-collar workers that I see coming and going. A broad demographic. We have got at least 4 gay male couples, one female partnership. A good cross section. And also nationalities" Resident 2

While praising the variety of residents within the apartment, there is no reference to children or comment on the lack of this group. While sexual orientation, employment and class were cited as categories, the lack of children did not warrant comment.

In interviews and media representations, children and parents with children are underrepresented in discussions of higher density housing. This is significant for urban planning and scholarship as representations, including omissions, can cultivate dominant assumptions about how the world works and how the world should be. According to Gerbner (1972, p. 44) "representation in the fictional world signifies social existence, absence means symbolic annihilation." Tuchman (1978) applied this notion to the 'symbolic annihilation' of women in American mass media, arguing that women were often omitted, trivialised or condemned in media representations that focused on and valorised men. A similar trend can be seen applied to children and families in high density housing that were, not completely omitted, but often forgotten in media representations or interview discussions.

\section{Families can live in apartments (with caveats)}

Despite the prevalence of a child-free representation of higher density housing, there is an emerging social representation that seeks to naturalise the notion of children from wealthy households in higher density environments. It is far more prevalent in newspaper reportage than interviews. One newspaper reports;

"The next generation of property buyers are not only content to raise a family in an apartment or townhouse, but are actively seeking out higher density, city-centric living options... younger Gen $X$ and Gen $Y$ buyers [are] gravitating to inner-city locations, placing higher value on proximity to the city and its amenities than a family-style home in the suburbs" (The Courier Mail, 2011)

While this quotation is explicitly stating notions that support the raising of children in inner-city locations, it draws upon conventional housing ideas to do so. Referencing 'family-style' houses in the suburbs serves to continue the divide between lifestyle-focused, city-centric options and familyfocused suburbs. Indeed, articles in the media designed to promote families in the city often draw upon consumption, convenience and lifestyle concepts rather than the community and family focused basis of suburban narratives. Comments on online articles even went so far as to accuse inner-city parents of being selfish, reflecting findings from the Netherlands that parents in higher density housing often have to defend their choices (Lilius, 2014).

This social representation is part of a broader appeal to 'the high life' that has previously been mostly associated with young professional singles and couples without children. However, middle class families are being increasingly targeted as desirable occupants for inner-city living (van den Berg, 2013). One newspaper article entitled "Families in the Sky" broached the capacity to raise children in 
high-rise apartments particularly explicitly (Edmistone, 2012). This article introduced three 'normal' families who had made the decision to trade a backyard for a balcony. The stories were full of references to babies crawling and teenage daughters heading out for a night on the town. These vignettes of normal family life occurred in three-bedroom apartments in Kangaroo Point, Morningside and Highgate Hill; high-value, inner-ring suburbs often considered Brisbane's key lifestyle precincts. The article profiled professional families with jobs in engineering, education and architecture. While families in higher density are normalised in this article, it appears this only extends to a certain class of family with particular lifestyle aspirations. This representation is at odds with research from Sydney and Melbourne that highlights the proportion of low-income families living in higher density housing (Randolph \& Tice, 2013). An interview with a developer reiterated this class divide. Reflecting on a focus group they had hosted as part of their market research strategy, a respondent from a large development company stated;

"If you are very early having kids you can stay in an apartment but once they start growing then everyone wants to move out to the suburbs. The older demographic has less opposition to living in apartments because their apartment is big enough because they can afford three bedrooms. Gen Y can't afford to have a big apartment." - Developer 4

Residents interviewed for this research raised the lack of family-appropriate apartments and commented on the deficit of three-bedroom apartments in Brisbane.

"It may be okay while you're at uni or you're single and you're just going to work every day and you're just coming home. But when you change your lifestyle just a little bit, I've noticed a lot of developments ... the apartment sizes are all pretty much the same. And so I'm saying to real estate agents, "well do you have a three-bedroom?" "Oh well we've only got these 3 options." I think there's not enough variety within the style of design and the sizes within those designs so that can also put a negative on people wanting to move because they may want more space." - Resident 3

Randolph predicted this challenge in 2006, arguing that apartment delivery is likely to cause segregation based on lifestyle and age as young professional couples and empty-nesters dominate renewed centres and families with children are consigned to the suburbs. While marketing strategies are beginning to embrace families with children, this appears to only extend to families that can afford the limited stock of larger apartments available in Brisbane.

\section{It's just economics}

This social representation uses a pragmatic economic rationale to justify the abundance of studios and one and two-bedroom apartments in Brisbane that aren't suitable for families. By anchoring apartments as investment products rather than as homes or dwellings, this social representation suggests that the lack of family-appropriate housing is an understandable outcome of market forces that may or may not change in the future. As one developer noted;

"As a developer, the easiest way to sell these things is to do one or two-bedrooms and sell them to investor groups in China, Sydney, Perth, because people are looking to spend the money and get the depreciation and tax benefits. That's why the majority of the apartments in the city are one bedrooms. Even though the need for owner occupiers might be quite the opposite the investor market is much bigger" - Developer 2 
This explicit acknowledgement of the contrast between investor appetite and owner-occupier needs was a common motif throughout the newspaper media and in interviews. The media featured explicit references to "investor-grade stock" while developers discussed differences in their development strategies based on whether they intended to target investors or owner-occupiers. As one planner explained;

"It's about the market cycle - the people who are going to buy the first round are the early investors and the finishes will be lower. That first round will never visit the apartment that they buy. Then it will go to the investors that will actually visit the apartment and the finishes have to be relatively decent. And the last round finally will be the people who will actually live there so the finishes will actually be quite high with the stone benches... Investors are statistically going to be looking for this market" - Planner 4

This trend was also spatially-differentiated and dependent on the scale of development. For example, high-value sites near the Brisbane River and boutique developments in the middle suburbs were deemed far more likely to attract owner-occupiers and to require two or three-bedroom units. As a developer stated;

"I don't think we design apartments with children in mind to the extent that we could. We certainly look at it in the context of the broader master plan. But if you a smaller developer you want to maximise the efficiency of your ground floor plate- how many apartments can I fit on the site? So you are going to do the smallest size second bedroom, not going to do a second bathroom if you can and not going to have many three bedroom apartments here because there are more owner occupiers close to the river." - Developer 3

Interviews in Brisbane revealed that designing for children is more often associated with the surrounding urban realm than the design of individual apartments or buildings. Interviews revealed a common focus on proximity to parks, public transport and shops as a way of mitigating the smaller size of apartments. While the focus on urban amenity is an important aspect of child-friendly cities, the lack of questioning of internal apartment design, size and location within a building is indicative of the lack of attention this aspect of design receives in Brisbane discussions.

Planners noted the lack of consideration of families as well. They referred to design decisions based on expected apartment occupants. As one planner explained;

"We don't design for kids in apartments but we don't design for almost anybody. The assumption is that it is your typical living space with two bedrooms and the market has to respond to what is going to fit a young married couple or two unrelated people living in a household." - Planner 2

This social representation is perpetuated through media framing that focuses on investment opportunities rather than the use value of homes. The newspaper media features references to investors as "the leading players in the market" and Chinese developers that "stake a major claim in Brisbane" (The Courier Mail, 2014), depicting housing development more as an investment opportunity than as meeting a need for shelter.

\section{Do it for the Kids}

This social representation anchors higher density housing in notions of housing supply and affordability, the generational divide between wealthy baby boomers and struggling millennials and 
the need for greater diversity in housing stock. The representation contrasts selfish, ignorant and wealthy low density dwellers with future generations who will need a 'leg up' in the property market. Central to this social representation is the belief that increasing housing supply is a key factor in improving housing affordability. In this way, they perceive of 'NIMBYs' (Not In My Back Yard) who oppose densification in their neighbourhoods as denying first home owners and renters an opportunity to access housing. A comment written on a Courier Mail article illustrates this viewpoint;

"We have a housing shortage and the easiest way to fix that would be to turn large blocks into smaller blocks. For people to dictate what other people do with their backyards while we have young people who can't afford homes anymore is amazingly selfish" - (Moore, 2013)

This is an example of a common-sense theory used to explain the need for higher densities in Brisbane. In a similar vein, interviews revealed a sub-section of participants who viewed higher density housing as a stepping stone on the way to the goal of owning a detached house or an inevitable aspect of their housing career. Interviews reflected a desire to avoid paying "dead money" in the form of rent and attendant strategies that involved purchasing an apartment in the short term before trading up when they had accrued more capital. As one resident explained, higher density housing is often chosen because it is the only affordable option;

"My kids are never going to afford a house - it freaks me out. I want this place paid off by the time the kids finish high school, then I can buy an apartment and when the kids want to buy they sell - live in it then sell when they want to buy their own places." - Resident 4

The appropriateness of medium density housing for a diverse range of households was also a common motif in the interviews and the newspaper media. While many noted the prevalence of 'NIMBY' opposition to higher density housing, planners noted an increasing acceptance of diversity in housing choices. As one planner explained;

"One of the good things that we have done is have a discussion about housing diversity and housing choices and what gets people is saying 'ok, you don't want smaller housing in your area. Do you want your children to be able to move out of home?' 'yea' 'do you want them to be able to live close to you?' 'yes, not too close but yes, close.'" - Planner 5

This quotation reflects an emerging focus on medium density housing as a necessary response to a need for diverse and affordable housing options. In this sense, medium density housing is anchored in notions of housing diversity, affordable housing, inclusive neighbourhoods and inevitable change. It also reflects a differentiation between high rise apartments, viewed predominantly as investor products and more 'human-scale,' medium density developments viewed as appropriate for young families and elderly households.

\section{Discussing the implications of these social representations}

There is an existing body of research that has identified the perception of children in higher density housing as an aberration (Fincher, 2004), or an opportunity for inner-city revitalisation (Warner \& Rukus, 2013). However, this research reveals that the overlapping common-sense understandings of children and higher density housing are highly nuanced and encompass a broad range of theories, categories and images. These theories, categories and images constitute the social representations circulating in society. Identifying the four social representations recounted in this paper is significant as social representations are "a form of knowledge, socially produced and shared, having practical ends, and competing for the construction of a common reality of a social ensemble" (Jodelet, 1989, p. 
36). Different groups compete for the ability to circulate and support their social representation or version of reality and competition often favours groups with the power and resources to promote their vision of a city. The 'practical ends' (Jodelet, 1989, p. 36) of these social representations are planning policies and urban development underpinned by assumptions about the 'normal family' and the 'appropriate urban form' for these households.

The social representations identified in this research provide greater insight into how higher density is interpreted and responded to in Brisbane, and its relation to children and families. Findings support an existing body of research that has remarked on the dominant child-free and lifestyle-based nature of higher density discourses. This representation is in stark contrast to the wholesome construction of suburban lifestyles (Davison, 2017) and serves to identify 'legitimate' high density dwellers and subjugate less legitimate occupants. The representation of inner-city and higher-density housing as dangerous and deviant is particularly damaging as parental fear for their child's safety can result in reduced independent mobility for children and unintended negative consequences for children's physical and psychological health (Foster et al., 2015). While the decision to live an 'urban lifestyle' in the inner city is increasingly acceptable, this choice is predominately associated with young urban professionals ('yuppies') who are either singles or couples without children (Lilius, 2014). As Kern (2007) has argued, attracting and retaining (childless) consumer citizens to the inner city articulates neatly with a neoliberal agenda of urban growth, competition, and commodification.

Despite this, wealthy and educated households that form part of the gentrifying 'creative class' are increasingly being targeted as desirable occupants of higher density housing (Sherry \& Easthope, 2016). In line with international examples (Karsten, 2003; van den Berg, 2013), this study reveals that there is a growing social representation that naturalises middle-class families remaining in higher density housing and suggests that families can live in apartments (with caveats). This decision is often linked to considerations of commute times, a sense of connectedness to inner-city areas and a rejection of suburban ideals. Child-friendly cities are being hailed as a way of retaining young professionals as they begin family formation (Warner \& Rukus, 2013). However, this movement is spatially delineated and based on class and income. In particular, developers and planners spoke of the greater likelihood of families and owner-occupiers dwelling in lower density developments in inner-city suburbs further from the CBD.

This trend is also reflected in recent ABS data that shows the degree of variation in the proportion of apartments that house children, ranging from 25\% in Ashgrove in Brisbane's inner north to 13\%, 9\% and $11 \%$ in Brisbane's three highest density suburbs of Kangaroo Point, New Farm and Fortitude Valley. These findings also correlate with interviews that highlighted the predominance of one and two-bedroom apartments in the inner city. Despite the strong focus on marketing for families in inner city areas, the proportion of families living in apartments greater than 4 storeys only increased by $1 \%$ between 2011 and 2016 in Brisbane. While increased marketing to and acceptance of wealthy households may result in a greater focus on child-friendly amenities and services such as schools, child-care facilities and parks that benefit all households, this research reveals the widely-shared notion that three-bedroom apartments are only accessible for wealthy, older families. This rhetoric belies the fact that higher density housing offers an important housing option for lower income households in Melbourne and Sydney (Easthope \& Tice, 2011; Randolph \& Tice, 2013) and Brisbane (SGS Economics and Planning 2017). This observation indicates social segregation based on lifestyle, household composition and wealth and may serve to force lower income households to the city periphery or necessitate over-crowding. 
The "It's just economics" social representation is perhaps the most worrying narrative to emerge from this research. The focus on investor appetite rather than the needs of housing occupants has implications for the design of housing and the proportion of one, two and three-bedroom apartments. While density per se is not detrimental to children (Carroll et al., 2011), specific design elements are required to make higher density living more attractive to families. These elements include direct outdoor access, expanded indoor spaces, consideration of surveillance opportunities and the design of balcony balustrades to prevent falls. As reflected in the development strategies explained by planners and developers, design elements are less likely to feature in the creation of apartments targeted at investors.

The 'It's just economics' social representation drew upon notions of market mechanisms, demand and supply and investment trends to virtually silence discussion of the lack of families in higher density housing. Similarly, interviews revealed a silencing of internal apartment design in creating childfriendly higher-density housing based on the assumption that the constraints of smaller apartments will be mitigated by access to parks, shops and other amenities. This is despite substantial research investigating building and unit-scale aspects of child-friendly apartment design (Marcus \& Sarkissian, 1986; Yates, 1995) and international examples of child-friendly housing design policy (City of Vancouver, 1992). In particular, the media and built form professionals referenced the reality of financing arrangements and investment decisions to explain the design and composition of apartments in Brisbane. This argument positions housing development as a reflection of investor appetite and reactions to risk rather than a consideration of occupier desires. Not only does this have immediate implications on the use of these homes, it also presents challenges for the long-term attractiveness of investor-focused higher density housing in Brisbane.

The "Do it for the kids" social representation indicates several underlying common-sense assumptions about housing, affordability, life-stages and ethics. It also highlights some of the other socio-economic processes driving its development and occupation. These include investment strategies, affordability imperatives and locational trade-off decisions. The social representation reveals a view that high and medium density housing is essential to allowing a new generation to access home ownership or make interim investment decisions to allow for future house purchases. For example, apartments or townhouses were categorised as 'stepping stones' on the way to the eventual ownership of a detached house. Discussions about children in higher density housing involved assumptions about older children beginning to move out of home and their aspirations to remain in desirable suburbs. In particular, planners and developers mentioned the value of highlighting housing diversity rather than density when discussing medium density development with community members. Discussions about multi-generational suburbs and housing diversity were frequently referenced by community members as acceptable reasons for moderate density increases. While high-rise apartments were often anchored in notions of investors and short-term tenants, interviews revealed a desire for medium density development suitable for down-sizing older households or young families. Similarly, implicit views about housing supply, housing affordability and the divide between wealthy home owners and struggling young renters was a common motif. There is a pervasive view that the key element impacting housing affordability is a lack of supply. Despite being substantially refuted by many scholars (Gurran \& Ruming, 2015), this rhetoric is common in policy debates and in common-sense explanations of housing affordability.

\section{Conclusion}

This paper revealed four key social representations pertaining to children in higher density housing in Brisbane. While the predominant social representation maintains a view of child-free higher density 
housing, there is an emerging assumption that wealthier households may choose to remain in higher density housing once they have children. This trend towards increased proportions of children in higher density housing is tempered by acknowledged affordability issues and a lack of larger two and three-bedroom apartment options. This was partially associated with market trends and the primacy of investor apartment product in Brisbane in the years since 2007. In contrast, the "Do it for the kids" social representation introduces notions of housing affordability, the inevitability of increased density and generational divides between wealthy baby boomers and disadvantaged Gen $Y$ households. These social representations contribute to the 'common-sense' assumptions that shape decisions about children in higher density housing.

The legacy of "child-blind" (Randolph, 2006, p. 5) planning has long been decried in Australia and elsewhere in the English-speaking world. This research suggests social representations are increasingly embracing the notion of children in higher density but only in relation to particular households and often only if it supports the predominant goal of investment outcomes. The research also indicates that perceptions and decisions about children in higher density housing goes beyond discussions of consumer preferences or affordability imperatives to encompass ideas about international investment flows, the ethics of housing supply and neighbourhood opposition, ideas about safety and familyfriendly locations and questions about ideal consumers. These social representations help to position children in higher density environments as inevitable, enviable or evil and are important mechanisms in influencing how cities are planned and how development occurs.

\section{References}

Amati, M., \& Taylor, L. (2010). From Green Belts to Green Infrastructure. Planning Practice \& Research, 25(2), 143-155. doi:10.1080/02697451003740122

Australian Bureau of Statistics. (2011). Census Quick Stats - 2011. ABS Quick Stats. Retrieved http://www.censusdata.abs.gov.au/census services/getproduct/census/2011/quickstat/3G BRI?opendocument

Australian Bureau of Statistics. (2017). Census. Retrieved 30 June2017 from http://www.abs.gov.au/census

Bauer, M. W., \& Gaskell, G. (1999). Towards a Paradigm for Research on Social Representations. Journal for the Theory of Social Behaviour, 29(2), 163-185.

Birrell, B., \& Healy, E. (2013). Melbourne's High rise Apartment Boom Melbourne: Monash University. Bourdieu, P. (1985). The social space and the genesis of groups. Theory and society, 14(6), 723-744.

Brisbane City Council. (2014). Brisbane City Centre Master Plan 2014 - A vision for our open city. Brisbane

Burchell, R. W., Listokin, D., \& Galley, C. C. (2000). Smart growth: More than a ghost of urban policy past, less than a bold new horizon. Housing Policy Debate, 11(4), 821-879. doi:10.1080/10511482.2000.9521390

Calligeros, M. (2010, March 30). Cosy communities key to livability. The Brisbane Times.

Carroll, P., Witten, K., \& Kearns, R. (2011). Housing Intensification in Auckland, New Zealand: Implications for Children and Families. Housing Studies, 26(3), 353-367. doi:10.1080/02673037.2011.542096

Christie, H., Smith, S. J., \& Munro, M. (2008). The Emotional Economy of Housing. Environment and Planning A, 40(10), 2296-2312. doi:10.1068/a39358

City of Vancouver. (1992). High-density housing for families with children guidelines. Vancouver: City of Vancouver. Retrieved from http://guidelines.vancouver.ca/H004.pdf

Costello, L. (2005). From Prisons to Penthouses: The Changing Images of High-Rise Living in Melbourne. Housing Studies, 20(1), 49-62. doi:10.1080/0267303042000308723 
Davison, G. (2017). 'Suburb is not a rude word in Australia': A Lexical History. In R. Harris \& C. Vorms (Eds.), What's in a Name? Talking about Urban Peripheries (Global Suburbanisms). Toronto: University of Toronto Press.

Easthope, H., \& Tice, A. (2011). Children in Apartments: Implications for the Compact City. Urban Policy and Research, 29(4), 415-434. doi:10.1080/08111146.2011.627834

Edmistone, L. (2012, September 16). Families in the sky. The Sunday Mail.

Elcheroth, G., Doise, W., \& Reicher, S. (2011). On the knowledge of politics and the politics of knowledge: How a social representations approach helps us rethink the subject of political psychology. Political Psychology, 32(5), 729-758.

Fincher, R. (2004). Gender and life course in the narratives of Melbourne's high-rise housing developers. Australian Geographical Studies, 42(3), 325-338.

Fincher, R. (2007). Is high-rise housing innovative? Developers' contradictory narratives of high-rise housing in Melbourne. Urban Studies, 44(3), 631-649.

Fincher, R., \& Gooder, H. (2007). At Home with Diversity in Medium-Density Housing. Housing, Theory and Society, 24(3), 166-182. doi:10.1080/14036090701374530

Fincher, R., \& Jacobs, J. M. (1998). Cities of difference. New York: Guilford Press.

Foster, S., Wood, L., Francis, J., Knuiman, M., Villanueva, K., \& Giles-Corti, B. (2015). Suspicious minds: Can features of the local neighbourhood ease parents' fears about stranger danger? Journal of Environmental Psychology, 42, 48-56.

Fullagar, S., Pavlidis, A., Reid, S., \& Lloyd, K. (2013). Living it up in the 'new world city': high-rise development and the promise of liveability. Annals of Leisure Research, 16(4), 280-296. doi:10.1080/11745398.2013.840946

Gerbner, G. (1972). Violence in television drama: Trends and symbolic functions. In G. A. Comstock \& E. Rubinstein (Eds.), Television and social behavior, Vol. 1, Content and control. Washington, D.C: U.S Government Printing Office

Gleeson, B., \& Sipe, N. (2006). Reinstating kids in the city. In B. Gleeson \& N. Sipe (Eds.), Creating Child Friendly Cities: reinstating kids in the city. New York: Routledge.

Goodsell, T. L. (2013). Familification: Family, Neighborhood Change, and Housing Policy. Housing Studies, 28(6), 845-868. doi:10.1080/02673037.2013.768334

Gurran, N., \& Ruming, K. (2015). Less planning, more development? Housing and urban reform discourses in Australia. Journal of Economic Policy Reform, 1-19.

Höijer, B. (2010). Emotional anchoring and objectification in the media reporting on climate change. Public Understanding of Science, 19(6), 717-731. doi:10.1177/0963662509348863

Howarth, C. (2001). Towards a social psychology of community: A social representations perspective. Journal for the Theory of Social Behaviour, 31(2), 223-238.

Howarth, C., Andreouli, E., \& Kessi, S. (2013). Social Representations and the politics of participation In K. Kinnvall, T. Capelos, H. Dekker, \& P. Nesbitt-Larking (Eds.), Palgrave Handbook of Global Political Psychology. London Palgrave.

Howley, P. (2009). Attitudes towards compact city living: Towards a greater understanding of residential behaviour. Land Use Policy, 26(3), 792-798. doi:http://dx.doi.org/10.1016/j.landusepol.2008.10.004

Jodelet, D. (1989). Folies et représentations sociales. Paris: Les Presses universitaires de France.

Jodelet, D. (1991). Madness and Social Representations (T. Pownall, Trans.). New York: Harvester Wheatsheaf.

Joffe, H. (2003). Risk: From perception to social representation. British Journal of Social Psychology, 42, 55-73.

Karsten, L. (2003). Family Gentrifiers: Challenging the City as a Place Simultaneously to Build a Career and to Raise Children. Urban Studies, 4O(12), 2573-2584. doi:10.1080/0042098032000136228

Kelly, J.-F. (2011). The housing we'd choose. Melbourne: T. G. Institute. 
Kern, L. (2007). Reshaping the Boundaries of Public and Private Life: Gender, Condominium Development, and the Neoliberalization of Urban Living. Urban Geography, 28(7), 657-681. doi:10.2747/0272-3638.28.7.657

Lambert, C., \& Boddy, M. (2010). City Center Housing in the UK: Prospects and Policy Challenges in a Changing Housing Market. disP - The Planning Review, 46(180), 47-59. doi:10.1080/02513625.2010.10557063

Langlois, P. (2012). Meaning, media and dwellings: the public image of the high-rise Toronto condo. (Doctor of Philosophy), University of Toronto, Toronto.

Lilius, J. (2014). Is There Room for Families in the Inner City? Life-Stage Blenders Challenging Planning. Housing Studies, 29(6), 843-861. doi:10.1080/02673037.2014.905673

Marcus, C. C., \& Sarkissian, W. (1986). Housing as if people mattered : site design guidelines for medium-density family housing: Berkeley : University of California Press, c1986.

Moore, T. (2013, February 23). Keep the humble backyard, says urban design expert. The Brisbane Time.

Moore, T. (2017). Families in city apartments: The social change our planners missed. Beaudesert Times. Retrieved from http://www.beaudeserttimes.com.au/story/4471406/families-in-cityapartments-the-social-change-our-planners-missed/?cs=7\#slide=3

Moscovici, S. (1973). Foreword. In C. Herzlich (Ed.), Health and illness: a social psychological analysis. London: Academic Press.

Newton, P., \& Glackin, S. (2014). Understanding Infill: Towards New Policy and Practice for Urban Regeneration in the Established Suburbs of Australia's Cities. Urban Policy and Research, 1-23.

Place Advisory. (2016). Market Report - Inner Brisbane Apartments Retrieved from http://www.placeprojects.com.au/wp-content/uploads/2017/02/Inner-Brisbane-

Apartment-Market-Report-December-Quarter-2016.pdf

Radu, M., \& Redien-Collot, R. (2008). The Social Representation of Entrepreneurs in the French Press: Desirable and Feasible Models? International Small Business Journal, 26(3), 259-298. doi:10.1177/0266242608088739

Randolph, B. (2006). Delivering the compact city in Australia: current trends and future implications. Urban Policy and Research, 24(4), 473-490. doi:10.1080/08111140601035259

Randolph, B., \& Tice, A. (2013). Who Lives in Higher Density Housing? A Study of Spatially Discontinuous Housing Sub-markets in Sydney and Melbourne. Urban Studies, 50(13), 26612681. doi:10.1177/0042098013477701

Raynor, K., Matthews, T., \& Mayere, S. (2015). Defining the density debate in Brisbane: how urban consolidation is represented in the media. Paper presented at the State of Australian Cities Conference, Gold Coast

Raynor, K., Matthews, T., \& Mayere, S. (2017). Shaping urban consolidation debates: Social representations in Brisbane newspaper media. Urban Studies, 54(6).

Raynor, K., Mayere, S., \& Matthews, T. (2017). Do 'city shapers' really support urban consolidation? The case of Brisbane, Australia. Urban Studies. doi:10.1177/0042098016688420

Reid, S., Lloyd, K., \& O'Brien, W. (2017). Women's perspectives on liveability in vertical communities: a feminist materialist approach. Australian Planner, 54(1), 16-23. doi:10.1080/07293682.2017.1297315

Revington, N., \& Townsend, C. (2016). Market Rental Housing Affordability and Rapid Transit Catchments: Application of a New Measure in Canada. Housing Policy Debate, 26(4-5), 864886. doi:10.1080/10511482.2015.1096805

Rowe, J. E. (2012). Auckland's urban containment dilemma: the case for green belts. Urban Policy and Research, 30(1), 77-91.

SGS Economics and Planning. (2017). The changing face of apartment living. Melbourne: SGS Economics and Planning. Retrieved from https://www.sgsep.com.au/publications/changingface-apartment-living-1 
Sherry, C., \& Easthope, H. (2016). Under-supply of schooling in the gentrified and regenerated inner city. Cities, 56, 16-23. doi:http://dx.doi.org/10.1016/i.cities.2016.02.008

Somerville, P. (1992). Homelessness and the Meaning of Home: Rooflessness or Rootlessness? International Journal of Urban and Regional Research, 16(4), 529-539. doi:10.1111/j.14682427.1992.tb00194.x

Steele, W., \& Dodson, J. (2014). Made in Queensland: planning reform and rhetoric. Australian Planner, 51(2), 141-150. doi:10.1080/07293682.2013.877511

The Courier Mail. (2011). Buyers seek city-centric living options. The Courier Mail.

Tuchman, G. (1978). Introduction: The Symbolic Annihilation of Women by the Mass Media. In G. Tuchman, A. K. Daniels, \& J. Benet (Eds.), Hearth and Home: Images of women in the mass media. New York: Oxford University Press.

van den Berg, M. (2013). City Children and Genderfied Neighbourhoods: The New Generation as Urban Regeneration Strategy. International Journal of Urban and Regional Research, 37(2), 523-536. doi:10.1111/j.1468-2427.2012.01172.x

Wagner, W., Duveen, G., Farr, R., Jovchelovitch, S., Lorenzi-Cioldi, F., Marková, I., \& Rose, D. (1999). Theory and Method of Social Representations. Asian Journal of Social Psychology, 2(1), 95125. doi:10.1111/1467-839X.00028

Wagner, W., \& Hayes, N. (2005). Everyday Discourse and Common Sense: the theory of social representations. New York: Palgrave Macmillan.

Warner, M. E., \& Rukus, J. (2013). Planners' Role in Creating Family-Friendly Communities: Action, Participation and Resistance. Journal of Urban Affairs, 35(5), 627-644. doi:http://onlinelibrary.wiley.com/journal/10.1111/\%28ISSN\%291467-9906/issues

Whitzman, C., \& Mizrachi, D. (2012). Creating Child-Friendly High-Rise Environments: Beyond Wastelands and Glasshouses. Urban Policy and Research, 30(3), 233-249. doi:10.1080/08111146.2012.663729

Yates, R. (1995). Child friendly housing : a guide for housing professionals. Vancouver: Society for Children and Youth of British Columbia. 